VOL. 4 NO. I

(April 2016)
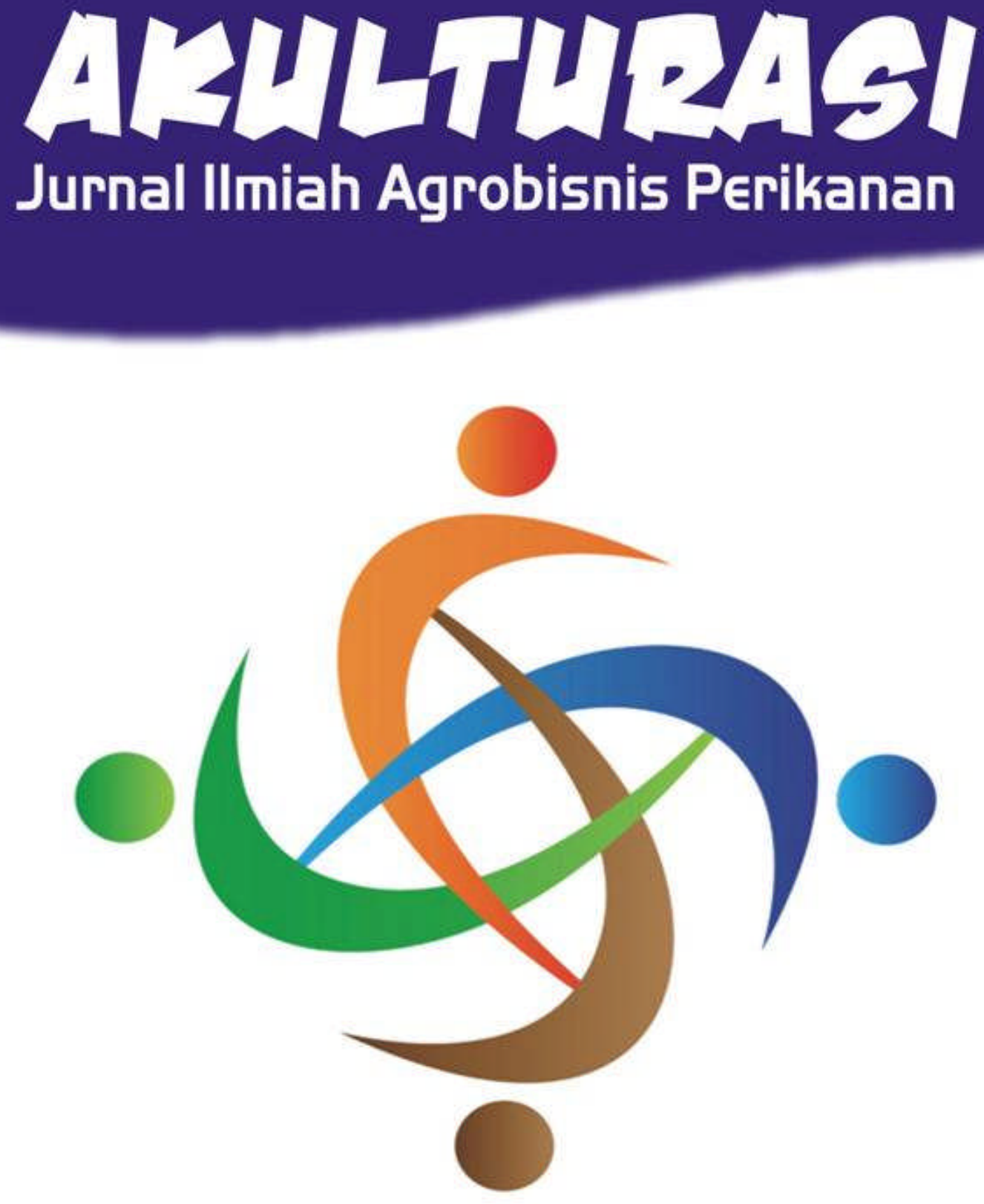

diterbitkan oleh PROGRAM STUDI AGROBISNIS PERIKANAN FAKULTAS PERIKANAN DAN ILMU KELAUTAN UNIVERSITAS SAM RATULANGI

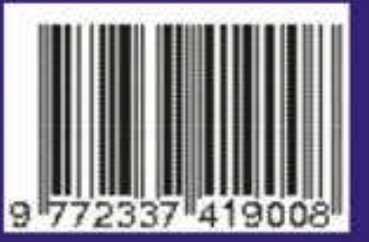




\section{AKULTURASI (Jurnal IImiah Agrobisnis Perikanan)}

Akulturasi merupakan Jurnal IImiah Agrobisnis Perikanan, diterbitkan dua kali setahun (April dan Oktober). Jurnal ini menerbitkan jurnal asli hasil penelitian di bidang sosial ekonomi perikanan dan kelautan. Selain itu jurnal AKULTURASI menerbitkan jurnal asli hasil penelitian di bidang agrobisnis kompleks (pertanian, peternakan dan kehutanan) terutama kajian aspek sosial ekonomi kemasyarakatan.

Susunan Dewan Redaksi Jurnal AKULTURASI, Berdasarkan SK. Dekan Fakultas Perikanan dan Ilmu Kelautan Universitas Sam Ratulangi Manado.

Pelindung :

Dekan Fakultas Perikanan dan Ilmu Kelautan Universitas Sam Ratulangi Manado

Ketua:

Prof. Dr. Ir. Eddy Mantjoro, M.Sc

Wakil Ketua:

Dr. Jardie A. Andaki, S.Pi., M.Si

Penyunting Pelaksana:

Ir. Lexy K. Rarung, M.Si

Ir. Jueldy Madjid, M.Si

Ir. Steelma V. Rantung, M.Si

Ir. Djuwita R.R. Aling, M.Si

Pelaksana Tata Usaha :

Roy Tumoka

Program Studi Agrobisnis Perikanan

FPIK UNSRAT Manado.

Jln. Kampus Bahu. Manado. 95115.

Telp: 081220942319 / 0431-868027

Fax: 0431-868027

e-mail : jardieandaki@unsrat.ac.id

Available online : http://ejournal.unsrat.ac.id/index.php/akulturasi 


\section{DAFTAR ISI}

Halaman

DAFTAR ISI

DAFTAR TABEL

ii

ANALISIS FINANSIAL USAHA IKAN ASAP PINEKUHE DI KABUPATEN

KEPULAUAN SANGIHE

$183-188$

Danny Rofiyanto Bue ; Jardie A. Andaki ; Djuwitha R.R. Aling

ANALISIS PENDAPATAN DAN SISTEM BAGI HASIL NELAYAN JARING INSANG (GILL NET) MALOS 3 DI KELURAHAN MALALAYANG SATU TIMUR KECAMATAN MALALAYANG KOTA MANADO

Rolandow L. Dauhan; Jardie A. Andaki ; Vonne Lumenta 


\section{DAFTAR TABEL}

Halaman

Tabel 1. Jumlah Kelompok Usaha Bersama Nelayan/Perikanan Tangkap di Kota Manado. 192

Tabel 2. Harga Ikan Hasil Tangkapan Kelompok Nelayan Malos Tiga Berdasarkan Jenis Ikan Ukuran Sedang.

Tabel 3. Pendapatan Kelompok Nelayan Malos Tiga Berdasarkan Jenis Ikan Ukuran Sedang. 


\title{
ANALISIS FINANSIAL USAHA IKAN ASAP PINEKUHE DI KABUPATEN KEPULAUAN SANGIHE
}

\author{
Danny Rofiyanto Bue1; Jardie A. Andaki2; Djuwitha R.R. Aling² \\ 1) Mahasiswa Fakultas Perikanan dan IImu Kelautan Universitas Sam Ratulangi, Manado. \\ 2) Staff Pengajar Fakultas Perikanan dan IImu Kelautan Universitas Sam Ratulangi, Manado. \\ Koresponden email : logitechbird13@.gmail.com
}

\begin{abstract}
Pinekuhe smoked fish business is often faced with the lack of capital and lack of management in an effort to increase production. The lack of efficient production processes in the suspect is a problem that arises due to ignorance of the fishermen in regulating the financial factors of production, that the maximum benefit is not achieved. Based on these things, then the problem can be formulated as follows: What are the factors that affect the business financial analysis of smoked fish Pinekuhe in the rate of business profits smoked fish Pinekuhe in Tahuna Sangihe Islands Regency. As well as how to optimize financial Pinekuhe smoked fish in order to achieve the maximum rate of profit. The purpose of this study, namely 1) make a financial analysis of smoked fish business Pinekuhe Tahuna on Sangihe Islands Regency and 3) to study the rate of profit on Pinekuhe smoked fish business.

Basic research will be used is a case study, the research form by studying a particular case in which the object is limited (Widi, 2010). The results showed that the sale of smoked fish "pinekuhe" conducted only in the area of Market Towo'e in Tahuna. Sales made in addition to the market Towo'o Tahuna also based on orders from customers. Based on the criteria of financial analysis efforts smoked fish "pinekuhe" in Tahuna eligible to run. Small-scale enterprises of smoked fish business "pinekuhe" causes the value of a little profit.
\end{abstract}

Keywords: pinekuhe, smoked fish, financial analysis

\begin{abstract}
Abstrak
Usaha ikan asap Pinekuhe seringkali dihadapkan pada keterbatasan modal dan kurangnya manajemen dalam upaya peningkatan produksi. Ketidak efisiennya proses produksi di duga merupakan suatu masalah yang timbul akibat ketidaktahuan nelayan dalam mengatur finansial pada faktor-faktor produksinya, sehingga keuntungan maksimal tidak tercapai. Berdasarkan hal-hal tersebut, maka dapat dirumuskan permasalahan sebagai berikut : Faktor apa saja yang berpengaruh pada analisis finansial usaha ikan asap Pinekuhe dalam tingkat keuntungan usaha ikan asap Pinekuhe di Tahuna Kabupaten Kepulauan Sangihe. Serta bagaimana cara mengoptimalkan finansial ikan asap Pinekuhe agar tercapai tingkat keuntungan secara maksimal. Tujuan penelitian ini, yaitu 1) membuat analisis finansial usaha ikan asap Pinekuhe Tahuna di Kabupaten Kepulauan Sangihe dan 3) mempelajari tingkat keuntungan pada usaha ikan asap Pinekuhe.

Dasar penelitian yang akan digunakan adalah studi kasus, yaitu bentuk penelitian yang dilakukan dengan cara mempelajari suatu kasus tertentu pada obyek yang terbatas (Widi, 2010). Hasil penelitian menunjukkan bahwa penjualan ikan asap "pinekuhe" dilakukan hanya di wilayah Pasar Towo'e di Tahuna. Penjualan dilakukan selain di Pasar Towo'o Tahuna juga dilakukan berdasarkan pesanan dari konsumen. Berdasarkan kriteria analisis finansial usaha ikan asap "pinekuhe" di Tahuna layak dijalankan. Skala usaha yang kecil dari usaha ikan asap "pinekuhe" menyebabkan nilai keuntungan sedikit.
\end{abstract}

Kata kunci: pinekuhe, ikan asap, analisis financial

\section{PENDAHULUAN}

Kegiatan perikanan merupakan kegiatan ekonomi, oleh sebab itu kegiatan produksi, pemasaran, dan konsumsi ada di dalamnya. Salah satu kegiatan perikanan yang ada di Indonesia adalah 
produksi dan pemasaran ikan asap. Kegiatan memproduksi dan memasarkan ikan asap tidak terlepas dari kegiatan penyimpanan dan pemesanan yang dilakukan oleh penjual dari pengolah produk ikan asap tersebut. Salah satu sifat dari hasil produk perikanan adalah mudah rusak atau cepat busuk, oleh sebab itu cara pemesanan mulai dari pembuatan ikan asap hingga sampai kepada penjual dan cara penyimpanan produk perikanan khususnya ikan asap perlu diperhatikan sehingga para penjual ikan asap tidak akan merasa rugi jika hasil produksinya tidak dapat dipasarkan dengan baik.

Tekhnologi pengasapan telah digunakan secara luas dalam pengolahan sebagai upaya pengeringan sekaligus sebagai penghasil aroma dan rasa pangan seperti : daging asap, ikan asap, produk barbeque seperti sate, ikan bakar dan lain sebagainya. Pengasapan merupakan cara pengolahan atau pengawetan dengan kombinasi perlakuan pengeringan dan pemberian senyawa kimia alami dari hasil pembakaran bahan bakar alami. Asap sendiri diartikan sebagi suatu suspensi partikel-partikel padat dan cair dalam medium gas. Melalui pembakaran akan terbentuk senyawa asap dalam bentuk uap dan butiran-butiran tar serta dihasilkan panas. Jadi, proses pengasapan juga termasuk pengawetan dengan cara kimiawi sebab bahan-bahan kimia dalam asap dimasukkan ke dalam makanan yang diawetkan.
Dalam rangka mencapai sasaran pembangunan perikanan, diperlukan upaya untuk mengembangkan usaha perikanan sehingga harus memperhatikan analisis finansial. Analisis ini penting untuk menjamin keberhasilan dan keberlanjutan usaha pengolahan ikan, khusus ikan asap.

\section{Tujuan Penelitian}

1. Membuat analisis finansial usaha ikan asap Pinekuhe Tahuna di Kabupaten Kepulauan Sangihe

2. Mempelajari tingkat keuntungan pada usaha ikan asap Pinekuhe

\section{Waktu Penelitian}

Waktu yang digunakan dalam pelaksanaan penelitian di mulai dari penyusunan rencana kerja hingga pelaksanaan ujian adalah sudah dimulai sejak 5 bulan, yaitu mulai dari bulan Maret sampai dengan bulan Juli 2015.

\section{METODOLOGI PENELITIAN}

Penelitian ini bersifat deskriptif yaitu penelitian yang menggambarkan semua data atau keadaan yang subyek/obyek penelitian (seseorang, lembaga, masyarakat dan lain-lain) kemudian dianalisis dan dibandingkan berdasarkan kenyataan yang sedang berlangsung pada saat ini dan selanjutnya mencoba untuk melakukan pemecahan masalahnya (Widi, 2010).

Dasar penelitian yang digunakan adalah studi kasus, yaitu bentuk penelitian 
yang dilakukan dengan cara mempelajari suatu kasus tertentu pada obyek yang terbatas (Widi, 2010). Dalam hal ini, studi kasus tentang analisis finansial usaha ikan asap Pinekuhe di Tahuna Kabupaten Kepulauan Sangihe.

Data yang sudah terkumpul diseleksi dan ditabulasi, selanjutnya dianalisa secara deskriptif. Analisis deskriptif dimaksud untuk memberikan bahasan atau penafsiaran terhadap datadata menggunakan perhitungan yang sederhana, seperti penjumlahan, perkalian, persentasi dan nilai rata-rata (Essty, 1998).

Modal Investasi :

\begin{tabular}{|c|l|r|}
\hline No. & \multicolumn{1}{|c|}{ Uraian } & \multicolumn{1}{|c|}{ Jumlah (Rp.) } \\
\hline 1. & Tempat pengasapan (tempat fufu) & 500.000 \\
\hline 2. & Loyang & 75.000 \\
\hline 3. & Ember & 65.000 \\
\hline 4. & Pisau & 15.000 \\
\hline 5. & Parang & 25.000 \\
\hline 6. & Kapak & 45.000 \\
\hline 7. & Keranjang & 48.000 \\
\hline 8. & Ruang pengasapan Jumlah & 150.000 \\
\hline \multicolumn{2}{|c|}{} & $\mathbf{9 2 3 . 0 0 0}$ \\
\hline
\end{tabular}

Tingkat Pendapatan

Berdasarkan hasil penelitian tingkat pendapatan usaha ikan asap "pinekuhe" di Tahuna adalah sebesar Rp. 52.000.000,- per tahun dalam 52 kali produksi (@ 100 ekor x Rp. 30.000). Perhitungan sebagai berikut :

$\left(\begin{array}{c}100 \\ 3\end{array}\right) \times 52 \times R p .30 .000=$

kp. 52.000 .000

Kapasitas tempat pengasapan 100 ekor, dijual per tumpukan 3 ekor selama

\section{HASIL DAN PEMBAHASAN}

Analisis finansial usaha ikan asap "pinekuhe" dilakukan berdasarkan langkah-langkah berikut :

\section{Modal Investasi}

Dalam menjalankan suatu usaha ikan asap "pinekuhe", hal yang sangat penting yang harus di sediakan oleh seorang pelaku usaha adalah modal. Modal merupakan dana awal dalam pembentukan suatu usaha. Modal usaha atau barang investasi usaha ikan asap "pinekuhe", dapat dilihat sebagai berikut : setahun produksi rata-rata 52 kali produksi dikali rata-rata harga jual Rp. 30.000, sehingga tingkat pendapatan Rp. 52.000.000.

\section{Struktur Biaya}

Biaya merupakan faktor yang menjadi dasar penetapan harga yang diterapakan pada produk. Perusahaan menginginkan agar harga yang di tetapakan dapat mencakup semua biaya untuk memproduksi, mendistribusikan, dan menjual produk serta tingkat laba yang 
sesuai dengan upaya yang dilakukan dan resiko yang dihadapi. Biaya merupakan elemen penting dalam strategi penetapan harga (Machfoedz, 2005).

Usaha ikan asap "pinekuhe", selain modal investasi pelaku usaha ikan asap "pinekuhe" di Tahuna dibebani biaya-biaya lain, seperti biaya tetap dan biaya tidak tetap.

\section{Biaya Tetap (fixed cost)}

Biaya Tetap (fixed cost)/ tahun
Menurut (Ibrahim, 2003) biaya tetap (fixed cost) adalah biaya yang tidak berubah selama proses produksi berlangsung, merupakan jenis biaya yang bersifat statis (tidak berubah) dalam ukuran tertentu. Biaya ini akan tetap dikeluarkan meskipun tidak melakukan aktivitas apapun. Lebih jelasnya dapat dilihat pada rincian biaya tetap sebagai berikut:

\begin{tabular}{|c|l|r|r|r|r|}
\hline No. Uraian & \multicolumn{1}{|c|}{ Pembelian } & \multicolumn{1}{c|}{$\begin{array}{c}\text { Umur } \\
\text { Ekonomi }\end{array}$} & \multicolumn{1}{c|}{ Nilai Sisa } & \multicolumn{1}{c|}{ Penyusutan } \\
\hline 1. & Tempat pengasapan (tempat fufu) & 500.000 & 20 & 100.000 & 30.000 \\
\hline 2. & Loyang & 75.000 & 3 & 0 & 25.000 \\
\hline 3. & Ember & 65.000 & 3 & 0 & 21.667 \\
\hline 4. & Pisau & 15.000 & 15 & 5.000 & 1.333 \\
\hline 5. & Parang & 25.000 & 15 & 5.000 & 2.000 \\
\hline 6. & Kapak & 45.000 & 15 & 5.000 & 3.333 \\
\hline 7. & Keranjang & 48.000 & 3 & 0 & 16.000 \\
\hline 8. & Ruang pengasapan & 150.000 & 10 & 0 & 15.000 \\
\hline \multicolumn{2}{|r|}{ Jumlah } & $\mathbf{9 2 3 . 0 0 0}$ & \multicolumn{2}{c|}{} & $\mathbf{1 1 4 . 3 3 3}$ \\
\hline
\end{tabular}

\section{Biaya Tidak Tetap (variabel cost)}

Menurut (Ibrahim, 2005) biaya tidak tetap (variabel cost) merupakan biaya yang berubah sepanjang proses produksi berlangsung, jenis biaya ini difungsikan untuk melengkapi biaya tetap dan bersifat dinamis. Biaya ini mengikuti banyaknya jumlah unit yang diproduksi ataupun banyaknya aktivitas yang dilakukan. lebih jelasnya dapat dilihat perincian sebagai berikut.

\begin{tabular}{|c|l|r|r|r|}
\hline No. & \multicolumn{1}{|c|}{ Uraian } & \multicolumn{1}{|c|}{ Pembelian } & Harga Satuan (Rp.) & \multicolumn{1}{c|}{ Jumlah } \\
\hline 1. & Bahan baku ikan (ekor) & 5.200 & 2.000 & 10.400 .000 \\
\hline 2. & Kayu bakar (tumpuk) & 52 & 100.000 & 5.200 .000 \\
\hline \multicolumn{7}{|c|}{ Jumlah } & 15.600 .000 \\
\hline \multicolumn{2}{|c|}{ TC = FC + VC } \\
\hline
\end{tabular}

\section{Analisis Kelayakan}

Mengetahui kelayakan dari usaha ikan asap yang dilakukan oleh pengusaha ikan asap "pinakuhe"di Tahuna maka, yang perlu diketahui terlebih dahulu adalah :
Investasi (I)

Biaya tetap (FC)

$=923.000$

Biaya tidak tetap (VC)

$=114.333$

Biaya total (TC)

$=15.600 .000$

Total penerimaan (TR) 
Dalam analisis finansial menggunakan rumus :

1. Operating Profit, rumus :

$\mathrm{OP}=\mathrm{TR}-\mathrm{VC}=52.0000 .000-15.600 .000=\mathrm{Rp} .36 .400 .000$

Keterangan :

$\mathrm{OP}=$ Keuntungan usaha

$\mathrm{TR}=$ Total penerimaan

$\mathrm{VC}=$ Biaya tidak tetap

Operating profit dari usaha ini sebesar Rp. 36.400.000, merupakan keuntungan yang diperoleh dan dapat digunakan untuk biaya produksi berikutnya.

2. Keuntungan usaha ikan asap "pinakuhe" yang dilakukan oleh pengusaha ikan asap di Tahuna sebesar,

Total Profit, rumus :

$\pi=\mathrm{TR}-\mathrm{TC}=52.000 .000-15.714 .333=\mathrm{Rp} .36 .285 .667$

Keterangan :

$\pi \quad=\quad$ Net profit

$\mathrm{TR}=$ Total penerimaan

$\mathrm{TC}=$ Biaya total

Net profit atau keuntungan absolut

sebesar Rp. 36.285.667 sehingga dapat di

jamin keberlangsungannya karena

keuntungan bersifat positif.

Profit rate (Tingkat keuntungan) :

$\frac{\pi}{T C} \times 100 \%=\frac{36.285 .667}{15.714 .333} \times 100 \%=230,91 \%$

Keterangan :

$$
\begin{aligned}
& \pi=\text { Total profit } \\
& T C=\text { Biaya total }
\end{aligned}
$$

Profit rate di peroleh sebesar 230,91\%, sehingga usaha yang dijalankan cukup menguntungkan.

Rentabilitas, rumus : $\frac{\pi}{i} \times 100 \%=\frac{36.285 .667}{923.000} \times 100 \%=3.931,27 \%$

Keterangan :

$\Pi=$ Total profit

I = Investasi

Benefit cost rasio, rumus : $B C R=T R / T C$

$$
B C R=\frac{T R}{T C}=3,31
$$

Keterangan :

TR = Hasil penjualan

$\mathrm{TC}=$ Biaya total

Nilai BCR untuk usaha pembenihan ikan mas lebih dari satu yaitu 3,31. Apabila nilai BCR lebih dari satu maka usaha ini layak untuk dijalankan.

Break event point atau titik impas dari usaha ikan asap "pinekuhe", sebagai berikut :

BEP Penjualan $=\frac{T C C}{1-\left(\begin{array}{l}V C \\ F R\end{array}\right)}=\frac{114.333}{1-\left(\begin{array}{l}13,300050 \\ G 2,200050\end{array}\right)}=\kappa p .163 .332,86$

$B E P^{\text {Satuan }}=\frac{\text { BEP Penjualan }}{\text { Harga Satuan }}=\frac{163.332,86}{30,000}=5,44$

Keterangan :

FC = Biaya tetap

$\mathrm{VC} \quad=$ Biaya tidak tetap

$\mathrm{TR}=$ Penerimaan total

Hasil analisis BEP Penjualan menggambarkan titik impas usaha ikan asap "pinekuhe" pada penjualan Rp. 163.332,86. Nilai ini merupakan nilai acuan penjualan yang harus dicapai pengusaha ikan asap "pinekuhe" untuk keuntungan nihil, artinya penjualan ikan asap harus lebih dari nilai BEP Penjualan.

Hasil analisis BEP Satuan menggambarkan titik impas usaha ikan 
asap "pinekuhe" pada produksi 5,44 ekor. Nilai ini merupakan nilai acuan produksi yang harus dicapai pengusaha ikan asap "pinekuhe" untuk keuntungan nihil, artinya produksi ikan asap harus lebih dari nilai BEP Satuan.

Jangka Waktu Pengembalian Investasi, rumus :

$\frac{I}{\pi} x n$ tahun $=\frac{923.000}{36.285 .667} \times 1=0,03$ tahun

Keterangan :

$$
\begin{array}{ll}
\mathrm{I} & =\text { Investasi } \\
\mathrm{n} & =\text { Tahun } \\
\mathrm{m} & =\text { Total profit }
\end{array}
$$

Hasil analisis untuk jangka waktu pengembalian investasi 0,03 tahun atau 0,36 bulan atau 10,8 hari. Nilai ini menunjukkan jika pengusaha ikan asap "pinekuhe", melakukan usaha selama 10,8 hari berturut, dengan asumsi struktur biaya, produksi dan harga penjualan konstan, maka pengembalian investasi dapat dilakukan selama 10,8 hari produksi.

\section{KESIMPULAN DAN SARAN}

\section{Kesimpulan}

1. Penjualan ikan asap "pinekuhe" dilakukan hanya di wilayah Pasar Towo'e di Tahuna. Penjualan dilakukan selain di Pasar Towo'o Tahuna juga dilakukan berdasarkan pesanan dari konsumen.

2. Berdasarkan kriteria analisis finansial usaha ikan asap "pinekuhe" di Tahuna layak dijalankan
3. Skala usaha yang kecil dari usaha ikan asap "pinekuhe" menyebabkan nilai keuntungan sedikit.

\section{Saran}

1. Potensi sumberdaya ikan dan bahan penunjang usaha ikan asap "pinekuhe" yang melimpah di Tahuna potensial dikembangkan untuk skala usaha yang lebih besar

2. Perlu adanya pemasaran sampai ke luar daerah.

\section{DAFTAR PUSTAKA}

Afrianto, E., E. Liviawaty, 1991. Pengawetan dan Pengolahan Ikan. Penerbit Kanasius. Yogyakarta.

Dahuri, R., 2001. Pengelolaan Sumberdaya Wilayah Pesisir dan Laut Secara Terpadu. Gramedia. Jakarta.

Fauzi, A., dan S. Anna. 2005. Pemodelan Sumberdaya Perikanan dan Kelautan untuk Analisis Kebijakan. PT. Gramedia Pustaka Utama, Jakarta.

Ibrahim. Y. M. H, 2003. Studi Kelayakan Bisnis. PT. Rineka Cipta. Jakarta.

Machfoedz. M, 2005. Kewirausahaan metode manajemen dan implementasi. BPFE Yokyakarta.

Monintja, D.R., dan R. Yusfiandayani, 2001. Pemanfaatan Sumberdaya Pesisir Dalam Bidang Perikanan Tangkap. Prosiding Pelatihan Pengelolaan Wilayah Pesisir Terpadu. IPB, Bogor.

Mulyadi. S. 2005. Analisis Ekonomi Usaha Nelayan dan Sistem Pengawetan/Pengolahan Ikan. Penerbit.PT. Raja Grafindo Persada Jakarta.

Tinungki, G. M., 2005. Evaluasi Model Produksi Surplus dalam Menduga Hasil Tangkapan Maksimum Lestari untuk Menunjang Pengelolaan Perikanan Lemuru di Selat Bali. Disertasi (tidak dipublikasikan). Sekolah Pascasarjana Institut Pertanian Bogor. Bogor. 


\title{
ANALISIS PENDAPATAN DAN SISTEM BAGI HASIL NELAYAN JARING INSANG (GILL NET) MALOS 3 DI KELURAHAN MALALAYANG SATU TIMUR KECAMATAN MALALAYANG KOTA MANADO
}

\author{
Rolandow L. Dauhan'; Jardie A. Andaki2; Vonne Lumenta² \\ 1) Mahasiswa Fakultas Perikanan dan Ilmu Kelautan Universitas Sam Ratulangi, Manado. \\ 2) Staff Pengajar Fakultas Perikanan dan IImu Kelautan Universitas Sam Ratulangi, Manado. \\ Koresponden email: olandauhan@gmail.com
}

\begin{abstract}
This study aims to: 1) analyze the income of fishermen gill nets in the group fishing Malos 3 in the Village Malalayang The Eastern District of Malalayang Manado and 2) determine the sharing system fisherman gill nets in the group fishing Malos 3 in the Village Malalayang The Eastern District of Malalayang City Manado.

Basic research is a case study, the research form by studying a specific case of the object is limited (Widi, 2010). The data were then processed and analyzed descriptively. According Sugiyono (2008), descriptive analysis method is the method used to analyze data in ways that describe or depict the data that has been collected as it is without intending to apply to general conclusions or generalizations. Descriptive analysis is intended to provide or penafsiaran discussion of the data for the conclusion. Descriptive data analysis gives an overview description of the sentences associated with the existing theory, through simple calculations like; the sum, average, and percentage.

The results of this study can be concluded: 1) The fishermen groups Malos 3 is a group of fishermen who have caught fish activity with various types of fishing gear, nets and fishing rods; 2) Activity Malos 3 fishermen's group, not just involve his fellow group members only, this is seen in the marketing activities of the catch is sold to the market's shoulders; 3) Revenue fishing groups based on the prevailing prices by applying the calculation of prices prevailing on the number of fish and fish bucket based on the unit; and 4) the sharing system adopts a group of fishermen equally common sense. Members of the group conducting fishing activities will inherit the same on the fish and the same amount of rupiah for fish sales results.
\end{abstract}

Keywords: Malos 3, fisherman, revenue, sharing system

\begin{abstract}
Abstrak
Penelitian ini bertujuan : 1) menganalisis pendapatan nelayan jaring insang dalam kelompok penangkap ikan Malos 3 di Kelurahan Malalayang Satu Timur Kecamatan Malalayang Kota Manado dan 2) mengetahui sistem bagi hasil nelayan jaring insang dalam kelompok penangkap ikan Malos 3 di Kel. Malalayang Satu Timur Kec. Malalayang Kota Manado.

Dasar penelitian yang digunakan adalah studi kasus, yaitu bentuk penelitian yang dilakukan dengan cara mempelajari suatu kasus tertentu pada obyek yang terbatas (Widi, 2010). Data yang diperoleh selanjutnya diolah dan dianalisis secara deskriptif. Menurut Sugiyono (2008), metode analisis deskriptif merupakan metode yang digunakan untuk menganalisis data dengan cara mendeskripsikan atau menggambarkan data yang telah terkumpul sebagaimana adanya tanpa bermaksud membuat kesimpulan yang berlaku untuk umum atau generalisasi.

Hasil penelitian ini dapat ditarik kesimpulan : 1) Kelompok nelayan Malos 3 merupakan kelompok nelayan yang memiliki aktivitas menangkap ikan dengan bebagai jenis alat tangkap, jaring dan pancing; 2) Aktivitas kelompok nelayan malos 3 , tidak hanya melibatkan sesama anggota kelompok saja, hal ini terlihat dalam aktivitas pemasaran hasil tangkapan dijual ke pasar Bahu; 3) Pendapatan kelompok nelayan didasarkan pada harga yang berlaku dengan menerapkan perhitungan harga yang berlaku terhadap jumlah ekor ikan maupun berdasarkan satuan ember ikan; dan 4) sistem bagi hasil kelompok nelayan menganut sistem sama rata sama rasa. Anggota kelompok yang melakukan aktivitas melaut akan mendapat bagian yang sama atas ikan hasil tangkapan maupun jumlah rupiah yang sama untuk ikan hasil penjualan.
\end{abstract}

Kata kunci : Malos 3, nelayan, pendpaatan, system bagi hasil 


\section{PENDAHULUAN}

Jaring insang merupakan salah satu jenis alat tangkap yang banyak digunakan oleh para nelayan, mulai dari jaring insang lingkar, jaring insang dasar, dan jaring insang permukaan. Usaha penangkapan ikan dengan menggunakan jaring insang sudah bukan merupakan teknologi yang baru bagi para nelayan, hal ini disebabkan karena bahannya lebih mudah diperoleh, secara teknis mudah dioperasikan, secara ekonomis bisa dijangkau oleh nelayan, dan lebih selektif terhadap ukuran ikan yang tertangkap.

Namun pengadaan alat tangkap ini ternyata masih mempunyai kendala dalam pembuatannya, disebabkan besarnya modal produksi. Kondisi ini terkait kemiskinan nelayan, terutama nelayan perorangan maupun buruh nelayan.

Beberapa hasil penelitian menunjukkan bahwa distribusi pendapatan dari pola bagi hasil tangkapan sangatlah timpang diterima antara pemilik dan awak kapal. Secara umum hasil bagi bersih yang diterima awak kapal dan pemilik kapal adalah setengah-setengah. Akan tetapi, bagian yang diterima awak kapal harus dibagi lagi dengan sejumlah awak yang terlibat dalam aktivitas kegiatan kapal.

Semakin banyak jumlah awak kapal, semakin kecil bagian yang diperoleh setiap awaknya. Selain itu pola umum bagi hasil di beberapa daerah menunjukkan pemilik selain mendapat setengah dari hasil tangkapan juga memperoleh $15 \%$ dari jumlah kotor hasiltangkapan sebagai cadangan jika ada kerusakan perahu ataupun jaring. Dengan demikian pemilik kapal (juragan darat) rata-rata menerima sekitar $65 \%$ dari keseluruhan hasil tangkapan. Sebaliknya rata-rata awak kapal akan mendapatakan hasil jauh lebih rendah dibandingkan yang diperoleh pemilik. Bagian untuk awak kapal tersebut dibagi berdasarkan porsi keterlibatannya secara khusus sebagai awak. Semakin banyak jumlah awak, semakin kecil yang diperoleh awak (Mulyadi, 2005)

Berdasarkan kondisi umum yang terjadi pada nelayan, khususnya buruh nelayan jaring insang, maka perlu dilakukan penelitian mengenai analisis pendapatan dan sistem bagi hasil. Penelitian ini diharapkan dapat memberikan gambaran tentang pendapatan dan sistem bagi hasil nelayan jaring insang yang bekerja dalam satu kelompok penangkap ikan Malos 3 di Kelurahan Malalayang Satu Timur Kecamatan Malalayang Kota Manado.

\section{Tujuan penelitian}

Berdasarkan

permasalahanpermasalahan penelitian ini mempunyai tujuan sebagai berikut :

1. Menganalisis pendapatan nelayan jaring insang dalam kelompok penangkap ikan Malos 3 di Kelurahan 
Malalayang Satu Timur Kecamatan Malalayang Kota Manado

2. Mengetahui sistem bagi hasil nelayan jaring insang dalam kelompok penangkap ikan Malos 3 di Kelurahan Malalayang Satu Timur Kecamatan Malalayang Kota Manado

\section{METODOLOGI PENELITIAN}

Penelitian ini bersifat deskriptif yaitu penelitian yang menggambarkan semua data atau keadaan yang subyek/obyek penelitian (seseorang, lembaga, masyarakat dan lain-lain) kemudian dianalisis dan dibandingkan berdasarkan kenyataan yang sedang berlangsung pada saat ini dan selanjutnya mencoba untuk melakukan pemecahan masalahnya (Widi, 2010).

Dasar penelitian yang digunakan adalah studi kasus, yaitu bentuk penelitian yang dilakukan dengan cara mempelajari suatu kasus tertentu pada obyek yang terbatas. Dalam hal ini, studi kasus tentang analisis efisiensi ekonomis soma landra rakit, pada Kelompok Nelayan Malos Tiga yang bertempat di Kelurahan Malalayang Satu Timur, Kecamatan Malalayang, Kota Manado.

\section{Analisis Data}

Data yang diperoleh selanjutnya diolah dan dianalisis secara deskriptif. Menurut Sugiyono (2008), metode analisis deskriptif merupakan metode yang digunakan untuk menganalisis data dengan cara mendeskripsikan atau menggambarkan data yang telah terkumpul sebagaimana adanya tanpa bermaksud membuat kesimpulan yang berlaku untuk umum atau generalisasi. Analisis deskriptif dimaksud untuk memberikan bahasan atau penafsiaran terhadap data-data untuk memperoleh kesimpulan.

Analisa data deskriptif memberikan gambaran keterangan dengan kalimatkalimat yang dihubungkan dengan teori yang ada, melalui perhitungan sederhana seperti; penjumlahan, rata-rata dan presentase.

\section{HASIL DAN PEMBAHASAN \\ Kelompok Nelayan di Kota Manado}

Menurut laporan Dinas Kelautan dan Perikanan Kota Manado (2013) bahwa Kelompok Usaha Bersama Nelayan/Perikanan Tangkap yang telah dikukuhkan sampai tahun 2012 adalah sebanyak 70 kelompok, dan yang telah pernah menerima bantuan sebanyak 35 kelompok. Jumlah kelompok pada tiap kelurahan disajikan dalam Tabel 1. 
Tabel 1. Jumlah Kelompok Usaha Bersama Nelayan/Perikanan Tangkap di Kota Manado

\begin{tabular}{|c|c|c|c|}
\hline No. & Kecamatan & Kelurahan & Jumlah Kelompok \\
\hline \multirow{4}{*}{1.} & \multirow{4}{*}{ Malalayang } & Malalayang Satu & 4 \\
\hline & & Malalayang Satu Timur & 7 \\
\hline & & Malalayang Dua & 1 \\
\hline & & Bahu & 1 \\
\hline \multirow{3}{*}{2.} & \multirow{3}{*}{ Sario } & Sario Tumpaan & 4 \\
\hline & & Titiwungan Selatan & 2 \\
\hline & & Titiwungan Utara & 1 \\
\hline 3. & Wenang & Wenang Selatan & 4 \\
\hline \multirow{5}{*}{4.} & \multirow{5}{*}{ Tuminting } & Sindulang Satu & 2 \\
\hline & & Sindulang Dua & 1 \\
\hline & & Bitung Karangria & 6 \\
\hline & & Tumumpa Dua & 4 \\
\hline & & Maasing & 2 \\
\hline \multirow{7}{*}{5.} & \multirow{7}{*}{ Bunaken } & Molas & 1 \\
\hline & & Tongkaina & 1 \\
\hline & & Manado Tua Satu & 8 \\
\hline & & Manado Tua Dua & 9 \\
\hline & & Siladen & 3 \\
\hline & & Bunaken & 6 \\
\hline & & Alungbanua & 3 \\
\hline & & & 70 \\
\hline
\end{tabular}

Sumber : Dinas Kelautan dan Perikanan Kota Manado (2011)

Kelompok Nelayan Malos Tiga

Kelompok Nelayan Malos Tiga di Kelurahan Malalayang Satu Timur Kecamatan Malalayang Kota Manado dikukuhkan pada tanggal 11 Mei 2011, dengan jumlah anggota saat itu adalah 10 orang dan sekarang telah bertambah menjadi 15 orang. Kata Malos itu sendiri berupa singkatan dari Malalayang Lorong Orang Sanger; karena sebagian besar masyarakat di wilayah tersebut adalah keturunan suku Sangihe.

Pendirian kelompok ini didasarkan atas kesadaran akan pentingnya kelompok nelayan dalam menanggulangi secara bersama-sama resiko usaha penangkapan. Resiko dimaksud, yaitu pembiayaan bersama atas barang modal, perawatan barang modal dan pertanggung jawaban penyaluran batuan dari pemerintah terkait.

Adanya kelompok akan mempermudah pemerintah terkait untuk melakukan monitoring dan evaluasi program batuan yang diberikan kepada kelompok nelayan. Kelompok Nelayan Malos Tiga telah mendapatkan hibah berupa satu set jaring insang permukaan yang digunakan secara bergiliran oleh anggota kelompok.

\section{Pendapatan Nelayan Kelompok Penangkap Ikan Malos 3 \\ Kelompok nelayan Malos Tiga merupakan kelompok nelayan penangkap ikan yang memiliki 15 anggota dan memiliki 15 perahu, jaring 10 buah, serta memiliki alat tangkap lainnya seperti pancing. Dalam kegiatan melaut satu}


kelompok terdiri 2 - 3 orang menuju tempat penangkapan di sekitar wilayah pantai.

Setelah proses persiapan, penangkapan ikan dan kembali ke daratan, hasil tangkapan berupa ikan dikumpulkan untuk dijual. Penjualan ikan dilakukan di pinggiran pantai menurut harga yang berlaku. Konsumen atau pembeli biasanya datang langsung ke Kelompok nelayan untuk melakukan transaksi pembelian. Pengukuran yang ditetapkan untuk penggambaran harga dilakukan berdasarkan jumlah ekor ikan dan atau pengukuran menggunakan ember.

Penggunaan pengukuran menurut jumlah ekor ikan dan pengukuran menggunakan ember, dilakukan menurut jumlah ikan hasil tangkapan. Jika ikan sedikit maka pengukuran menggunakan jumlah ekor ikan yang dipakai, dan jika musim ikan baik maka pengukuran yang digunakan ialah jumlah ember ikan yang dapat ditampung.

Penangkapan menggunakan jaring insang permukaan pada Kelompok Nelayan Malos Tiga, menghasilkan ikanikan pelagis kecil dan sedang. Hasil pengamatan di lokasi penelitian, diidentifikasi jenis-jenis ikan pelagis yang sering tertangkap menggunakan jaring insang permukaan pada Kelompok
Nelayan Malos Tiga, yaitu : selar, layang, tongkol, dan lahoma.

Pendapatan Kelompok Nelayan Malos Tiga ditentukan berdasarkan hasil penjualan ikan hasil tangkapan, yaitu :

Tabel 2. Harga Ikan Hasil Tangkapan Kelompok Nelayan Malos Tiga Berdasarkan Jenis Ikan Ukuran Sedang.

\begin{tabular}{|c|l|c|c|}
\hline \multirow{2}{*}{ No. } & \multirow{2}{*}{ Jenis Ikan } & \multicolumn{2}{|c|}{ Rata-rata Harga } \\
\cline { 3 - 4 } & & per Ekor & per Ember \\
\hline 1. & Selar & 2.000 & 250.000 \\
\hline 2. & Layang & 1.500 & 200.000 \\
\hline 3. & Tongkol & 2.000 & 200.000 \\
\hline 4. & Lahoma & 2.500 & 250.000 \\
\hline
\end{tabular}

Sumber : Data Primer (2015)

Berdasarkan tabel ini, jika diasumsikan jumlah trip 10 kali dalam satu bulan, dengan 10 bulan operasi penangkapan ikan, maka terdapat 100 kali operasi penangkapan ikan. Hasil pengamatan di lokasi penelitian rata-rata penangkapan jika saat sulit ikan hasil tangkapan berkisar 30 - 50 ekor, dan jika musim baik hasil tangkapan berkisar 3 - 5 ember ikan. Dengan demikian pendapatan Kelompok Nelayan Malos Tiga (Tabel 3). Berdasarkan tabel ini pendapatan Kelompok Nelayan Malos Tiga jika penjualan menggunakan satuan ekor ikan berkisar Rp. $\quad 5.000 .000$ sampai Rp. 7.500.000 per tahun. Sedangkan menggunakan penjualan menggunakan satuan ember berkisar Rp. 50.000 .000 sampai Rp. 75.000 .000 per tahun. 
Tabel 3. Pendapatan Kelompok Nelayan Malos Tiga Berdasarkan Jenis Ikan Ukuran Sedang.

\begin{tabular}{|c|l|c|c|c|c|c|c|}
\hline \multirow{2}{*}{ No. } & \multirow{2}{*}{ Jenis Ikan } & \multicolumn{2}{|c|}{ Rata-rata Harga } & \multicolumn{2}{c|}{ Pendapatan per Trip } & \multicolumn{2}{c|}{ Pendapatan per Tahun } \\
\cline { 3 - 8 } & & per Ekor & per Ember & per 50 Ekor & per 5 Ember & per 50 Ekor/thn & per 5 Ember/thn \\
\hline 1. & Selar & 1.500 & 150.000 & 75.000 & 750.000 & 7.500 .000 & 75.000 .000 \\
\hline 2. & Layang & 1.000 & 150.000 & 50.000 & 750.000 & 5.000 .000 & 75.000 .000 \\
\hline 3. & Tongkol & 1.250 & 100.000 & 62.500 & 500.000 & 6.250 .000 & 50.000 .000 \\
\hline 4. & Lahoma & 2.000 & 150.000 & 100.000 & 750.000 & 10.000 .000 & 75.000 .000 \\
\hline
\end{tabular}

Sumber : Data Primer (2015) hasil olahan

\section{Sistem Bagi Hasil}

Penangkapan ikan yang dilakukan Kelompok Nelayan Malos Tiga dilakukan bagi hasil sebelum dijual dan atau sesudah penjualan. Kedua sistem bagi hasil ini dilakukan berdasarkan kesepakatan angota kelompok yang melakukan aktivitas melaut. Pilihan membagi hasil sebelum penjualan dilakukan jika hasil tangkapan kurang. Sedangkan setelah penjualan jika hasil tangkapan ikan banyak.

Sistem bagi hasil sebelum penjualan biasanya hanya untuk ikan konsumsi sendiri. Kurangnya hasil tangkapan membuat jumlah ikan tidak layak dijual, lebih baik ikan hasil tangkapan dijadikan lauk-lauk untuk kebutuhan rumah tangga anggota kelompok yang melakukan aktivitas melaut. Ikan hasil tangkapan yang kurang jika dijual kemungkinan hasil yang didapatkan tidak dapat dijadikan modal untuk pembelian bahan kebutuhan rumah tangga, bahkan membeli ikan untuk lauklauk. Kondisi inilah yang menyebabkan pilihan membagi ikan sebelum penjualan dilakukan untuk memberikan pilihan kepada anggota kelompok, apakah hasil pembagian ikan akan dijual atau hasilnya digunakan untuk konsumsi.

Sistem bagi hasil dilakukan setelah penjualan dilakukan pada hasil tangkapan banyak. Jumlah hasil tangkapan banyak atau melimpah menjadi sasaran konsumen untuk membeli. Pedagang pengumpul, konsumen rumah tangga merupakan pembeli potensial untuk hasil tangkapan melimpah dari anggota kelompok nelayan Malos Tiga. Sistem penjualan mengikuti pengukuran jumlah ekor ikan dan atau pengukuran menggunakan satuan ember. Hasil penjualan ikan kemudian dibagi sama rata terhadap anggota kelompok yang melakukan aktivitas melaut.

Pembagian hasil penjualan $50: 50$ telah menjadi kesepakatan bersama. Anggota kelompok yang turun melaut akan mendapat bagian yang sama banyak atau sama jumlah rupiah yang diterima. Sistem ini juga berlaku pada pembagian sebelum penjualan untuk ikan maupun pembagian setelah penjualan untuk jumlah rupiah tertentu.

Fenomena bagi hasil sama rata sama rasa menghilangkan hirarki struktur organisasi. Baik ketua maupun anggota memiliki hak yang sama dalam bagi hasil 
penangkapan. Kondisi ini menjadi sebuah kenyataan terkait jaring insang permukaan yang digunakan untuk operasi penangkapan ini merupakan hibah dari pemerintah terkait. Hibah dalam bentuk jaring insang permukaan untuk operasi penangkapan dipandang anggota kelompok sebagai barang modal bersama dan menjadi milik bersama. Sehingga hasil penangkapan menggunakan jaring insang permukaan hasil hibah pemerintah harus dibagi sama rata sama rasa.

\section{KESIMPULAN DAN SARAN}

\section{Kesimpulan}

1. Kelompok nelayan Malos 3 merupakan kelompok nelayan yang memiliki aktivitas menangkap ikan dengan bebagai jenis alat tangkap, jarring dan pancing.

2. Aktivitas kelompok nelayan malos 3 , tidak hanya melibatkan sesama anggota kelompok saja, hal ini terlihat dalam aktivitas pemasaran hasil tangkapan dijual ke pasar Bahu.

3. Pendapatan kelompok nelayan didasarkan pada harga yang berlaku dengan menerapkan perhitungan harga yang berlaku terhadap jumlah ekor ikan maupun berdasarkan satuan ember ikan

4. Sistem bagi hasil kelompok nelayan menganut sistem sama rata sama rasa. Anggota kelompok yang melakukan aktivitas melaut akan mendapat bagian yang sama atas ikan hasil tangkapan maupun jumlah rupiah yang sama untuk ikan hasil penjualan.

\section{Saran}

1.Perlu adanya iuran atau persentase potongan hasil penjualan untuk pemeliharaan barang modal berupa jaring, perahu dan peralatan lainnya

2. Perlu adanya penambahan barang modal guna meningkatkan pendapatan dan kesempatan meraih keuntungan pada anggota kelompok nelayan.

\section{DAFTAR PUSTAKA}

Dahuri, R. (2000) Pendayagunaan Sumberdaya Kelautan Untuk Kesejahteraan Rakyat. Jakarta: Penerbit Lembaga Informasi dan Studi Pembangunan Indonesia. Dinas Kelautan, Perikanan,

Hernanto, F. 1995. IImu usahanelayan. Penebar Swadaya. Jakarta.

Nikijuluw, V. P. H. 2001. Potensi dan sosial ekonomi masyarakat pesisir serta strategi pemberdayaan mereka dalam konteks pengelolaan sumberdaya pesisir secara terpadu. Makalah pada Pelatihan Pengelolaan Pesisir Terpadu. Proyek Pesisir, Pusat kajian sumberdaya pesisir dan laut, Institut Pertanian Bogor (IPB) 17 halaman.

Purwanto, E.A.2007. Metode penelitian kuantitatif untuk administrasi public dan masalah - masalah sosial. Yogyakarta. Penerbit Gaya Media.

Rachman,A. 1982. Rencana pemerintah dalam pengembangan perikanan laut di Indonesia dalam hubungannya dengan implementasi wawasan Nusantara.. Depertemen Jakarta. 25 hal.

Raharjo Y. (1996) Community Base Management di Wilayah Pesisir Indonesia. Makalah pelatihan ICZPM. PKSPL-IPB dan Ditjen Bangda Depdagri. Tim Pemberdayaan Masyarakat Pesisir $P$

Satria, A.2009. Ekologi Politis Nelayan Yogyakarta LKIS.

Suhardiyono, L. 1992. Penyuluhan petunjuk bagi penyuluhan pernelayanan. Erlangga. Jakarta. 
ARULTURASI

Available online :http://ejournal.unsrat.ac.id/index.php/akulturasi 